\title{
Corrigendum: Testosterone Acts Within the Medial Amygdala of Rats to Reduce Innate Fear to Predator Odor Akin to the Effects of Toxoplasma gondii Infection
}

\author{
Dhiraj Kumar Singh, Shantala Arundathi Hari Dass, Samira Abdulai-Saiku and Ajai Vyas* \\ School of Biological Sciences, Nanyang Technological University, Singapore, Singapore
}

Keywords: androgen, behavioral manipulation, defensive behaviors, parasites, pheromones, semiochemicals

\section{A Corrigendum on}

\section{OPEN ACCESS}

Edited and reviewed by:

Erica Duncan,

Emory University, United States

*Correspondence:

Ajai Vyas

avyas@ntu.edu.sg

Specialty section:

This article was submitted to

Molecular Psychiatry,

a section of the journal

Frontiers in Psychiatry

Received: 03 July 2021

Accepted: 06 August 2021

Published: 09 September 2021

Citation:

Singh DK, Hari Dass $S A$, Abdulai-Saiku S and Vyas A (2021)

Corrigendum: Testosterone Acts Within the Medial Amygdala of Rats to Reduce Innate Fear to Predator Odor Akin to the Effects of Toxoplasma gondii Infection.

Front. Psychiatry 12:735656. doi: 10.3389/fpsyt.2021.735656
Testosterone Acts Within the Medial Amygdala of Rats to Reduce Innate Fear to Predator Odor Akin to the Effects of Toxoplasma gondii Infection

by Singh, D. K., Hari Dass, S. A., Abdulai-Saiku, S., and Vyas, A. (2020). Front. Psychiatry 11:630. doi: $10.3389 /$ fpsyt.2020.00630

In the original article, there was an error. The testosterone concentration in section Materials and Methods was stated to be $25 \mathrm{mM}$. This testosterone concentration related to the stock solution instead, which was further diluted 33 times.

A correction has been made within a single line in the section Materials and Methods, subsection Testosterone Supplementation Experiment, first paragraph:

Osmotic pumps were placed subcutaneously and connected thorough cannulas to supply either testosterone ( $25 \mathrm{mM}$ ethanol stock solution diluted to 3\% in artificial cerebrospinal fluid) or placebo (3\% ethanol solution in artificial cerebrospinal fluid) to the medial amygdala (ALZET Osmotic Pumps, USA).

The authors apologize for this error and state that this does not change the scientific conclusions of the article in any way. The original article has been updated.

Publisher's Note: All claims expressed in this article are solely those of the authors and do not necessarily represent those of their affiliated organizations, or those of the publisher, the editors and the reviewers. Any product that may be evaluated in this article, or claim that may be made by its manufacturer, is not guaranteed or endorsed by the publisher.

Copyright (C) 2021 Singh, Hari Dass, Abdulai-Saiku and Vyas. This is an open-access article distributed under the terms of the Creative Commons Attribution License (CC BY). The use, distribution or reproduction in other forums is permitted, provided the original author(s) and the copyright owner(s) are credited and that the original publication in this journal is cited, in accordance with accepted academic practice. No use, distribution or reproduction is permitted which does not comply with these terms. 